\title{
Price Forecasting in Chilli Crop in Major Markets of Karnataka State, India
}

\author{
H. S. Praveen Kumar ${ }^{1}$, Prabhuling Tevari ${ }^{2} *$ Devendra Beeraladinni $^{3}$ \\ and Shivanand Kammar ${ }^{4}$
}

${ }^{1}$ Department of Agricultural Economics, Agricultural College, UAS Raichur Karnataka, India

${ }^{2}$ Agriculture Research Station, Siruguppa, UAS Raichur, Karnataka, India

${ }^{3}$ Department of Agricultural Economics, UAS Raichur, Karnataka, India

${ }^{4}$ Department of Agricultural Extension Education, UAS, Raichur, Karnataka, India

*Corresponding author

\section{Keywords}

Price forecasting, Chilli crop, Major Markets, Karnataka

\section{Article Info}

Accepted:

26 April 2020

Available Online:

10 May 2020

\section{A B S T R A C T}

Prices perform a number of functions in an economic system. As allocator of resources, signalling to both producers and consumers regarding the level of agricultural production and consumption, as a distributor of income and as an influence on capital formation.Box-Jenkins ARIMA model is used to forecast the chilli price in selected markets for six months. Forecasted price of chilli in Bengaluru and Hubli market are increasing gradually over the month but in Byadgi and Mysore market prices are slightly fluctuating. By using information regarding the forecasted prices famers can plan to sell his product is specific market, market intermediaries/merchants can plan for storage for the commodity based on the forecasted price and in turn arrivals. Market committee to arrange for the basic needs like market yard, storage etc. to the farmers who come for the sell their commodity.

\section{Introduction}

Agricultural marketing plays a significant role in the movement of commodity from the producer to the consumer and in stabilizing the prices. Marketing plays, an important role in the economic development as it stimulates production, avoids unnecessary fluctuation in output and prices and reduces costs of production. However, for attaining these benefits, marketing system and marketing technology have to keep pace with the production technology and socio-economic development of the country.

Markets play important roles in facilitating the exchange of goods and services and can be welfare enhancing for actors engaged in the exchanges. Markets also provide signals about the true cost of resources and guide 
allocation to their best use. In addition to signals about the value of resources, integrated markets could help in equalizing the value of a resource across space after accounting for transfer costs between markets.

Prices perform a number of functions in an economic system. According to Mellor (1968), the three main functions of agricultural prices are to serve as an allocator of resources, signalling to both producers and consumers regarding the level of agricultural production and consumption, as a distributor of income and as an influence on capital formation. In a competitive economy, the pricing mechanism provides the signals to the producers in deciding what and how much has to be produced with the available resources for maximization of welfare. A particular movement of agricultural prices may facilitate the achievement of certain goals, while the same movement may operate against some other goal. For example, a steep rise in the price of food grains may full fill the goal of remunerative price to the farmers but it might adversely affect the standard of living of agricultural labourers, other wage earners and non-farm consumers who buy the food grains. Therefore, a continuous watch on prices is necessary in all societies.

The fluctuating characteristic of agricultural prices leads to instability. It must be clearly understood that all changes in prices do not imply instability. Since prices enter directly in the decision- frame of farmers; both in production and marketing decisions, fluctuation or instability in prices is the greatest source of risk, next only to weather

Hence it's important to know about the forecasted price of specific commodity in specific market to plan for marketing of commodity and to fetch the competitive price for the agricultural commodity.

\section{Materials and Methods}

\section{Box-Jenkins models}

The Box-Jenkins procedure is concerned with fitting a mixed Auto Regressive Integrated Moving Average (ARIMA) model to a given set of data. The main objective in fitting this ARIMA model is to identify the stochastic process of the time series and predict the future values accurately.

\section{Stationary and non-stationarity}

The term stationary meaning that the process generating the data is in equilibrium around a constant value and that the variance around the mean remains constant over time. The data must be roughly horizontal along time axis.

If mean changes over time (with some trend cycle pattern) and variance is not reasonably constant then series is non-stationary in both mean and variance.

If a time series is not stationary, then it can be made more nearly stationary by taking the first difference of the series. Conversely a stationary process may be summed or integrated to give a non-stationary process.

\section{ARIMA models}

Some time series exhibit perceptible periodic pattern for instance price and arrivals of agricultural commodities usually have a seasonal pattern process then the general.

The mixture of AR and MA seasonal model is

$\emptyset_{\mathrm{p}}(\mathrm{B}) \Delta^{\mathrm{d}} \emptyset_{\mathrm{p}}\left(\mathrm{B}^{\mathrm{s}}\right) \Delta^{\mathrm{d}} \mathrm{x}_{\mathrm{t}}=\theta_{\mathrm{q}}(\mathrm{B}) .(\mathrm{H}) \mathrm{Q}\left(\mathrm{B}^{\mathrm{s}}\right)$ et $\ldots \ldots \ldots$ (3.9)

If $\mathrm{Yt}=\Delta^{\mathrm{d}} \Delta^{\mathrm{d}} \mathrm{x}_{\mathrm{t}}-$ the model becomes an integrated model. 
The main stages in setting up a Box-Jenkins forecasting model are as follows.

1. Identification

2. Estimating the parameters

3. Diagnostic checking and

4. Forecasting

\section{Identification of models}

Before estimating the parameter $(\mathrm{p}, \mathrm{q})$ of model, the data are not examined to decide about the model which best explains the data. This is done by examining the sample ACF (Autocorrelation function) and PACF (Partial Autocorrelation function) of differenced series Yt.

\section{Estimation of parameters}

After tentatively identifying the suitable model, next step is to obtain Least Square Estimates of the parameters such that the error sum of squares is minimum.

$\mathrm{S}(\theta, \emptyset)=\sum_{\mathrm{t}=1}^{\mathrm{n}^{\mathrm{n}} \text { et } 2}(\theta, \emptyset) \ldots(3.11)$

where,

$$
\mathrm{t}=1,2,3, \ldots \mathrm{n}
$$

\section{Diagnostic checking}

After having estimated the parameters of a tentatively identified ARIMA model, it is necessary to do diagnostic checking to verify that the model is adequate.

Examination ACF and PACF of residuals may show an adequacy or inadequacy of the model. If it shows random residuals, then it indicates that the tentatively identified model is adequate. When an inadequacy is detected, the checks should give an indication of how the model need be modified, after which further fitting and checking takes place.

\section{Forecasting}

After satisfying about the adequacy of the fitted model, it can be used for forecasting. Forecasts based on the model.

$$
(1-\varnothing B)(1-\varphi B)^{s} Y t=(1-\theta B)\left(1-(H)^{s} B\right) \text { et. } .
$$

\section{Results and Discussion}

\section{Forecasting of prices of chilli in selected markets}

As Box-Jenkins model was preferred to the multiplicative time series model for forecasting purpose and it was used for forecasting of prices of chilli in selected markets. The results are presented below.

Model with the least AIC and SBC is selected and forecast of that model was considered
$(1,1,0)$ for Bengaluru market
$(2,1,0)$ for Byadgi market
$(2,1,0)$ for Hubli market
$(2,1,0)$ for Mysore market.

\section{Estimation of parameters}

Parameters of all the four markets of selected model are presented in Table 1 to 4 . After identifying the models tentatively, the next step is to obtain the estimates by the method of least squares estimates of the parameters $\varphi$ and $\theta$ being auto regressive and moving average terms respectively through iterative process.

\section{Diagnostic checking}

Individual autocorrelation of errors were examined for their significance and the overall significance was tested using BoxLjung statistic. It can be seen from the Table 5 none of the autocorrelation coefficients are 
significantly different from the zero at a reasonable level even if some of their significant values were not captured within the 95 per cent level of confidence interval, only Hubli market price was statistically significant at ten per cent. The results of the validation process implied that the information on the current periods chilli prices were sufficient to forecast the next period's prices.

Table.1 Estimation of parameters Bangalore market

\begin{tabular}{|l|c|c|c|c|c|}
\hline \multicolumn{7}{|c|}{ Conditional Least Squares Estimation } \\
\hline Parameter & Estimate & Standard Error & t Value & Approx Pr $>|\mathbf{t}|$ & Lag \\
\hline MU & -32.8226 & 88.6193 & -0.37 & 0.7116 & 0 \\
\hline AR1,1 & -0.1208 & 0.0761 & -1.59 & 0.1144 & 1 \\
\hline
\end{tabular}

Table.2 Estimation of parameters Byadgi market

\begin{tabular}{|l|c|c|c|c|c|}
\hline \multicolumn{5}{|c|}{ Conditional Least Squares Estimation } \\
\hline Parameter & Estimate & Standard Error & t Value & Approx Pr $>|\mathbf{t}|$ & Lag \\
\hline MU & -2.0779 & 42.4816 & -0.05 & 0.9610 & 0 \\
\hline AR1,1 & -0.1311 & 0.0778 & -1.69 & 0.0937 & 1 \\
\hline AR1,2 & -0.1405 & 0.0780 & -1.80 & 0.0735 & 2 \\
\hline
\end{tabular}

Table.3 Estimation of parameters of Hubli market

\begin{tabular}{|l|c|c|c|c|c|}
\hline \multicolumn{7}{|c|}{ Conditional Least Squares Estimation } \\
\hline Parameter & Estimate & Standard Error & t Value & Approx Pr $>|\mathbf{t}|$ & Lag \\
\hline MU & -14.9034 & 80.5726 & -0.18 & 0.8535 & 0 \\
\hline AR1,1 & -0.3279 & 0.0780 & -4.20 & $<.0001$ & 1 \\
\hline AR1,2 & 0.0225 & 0.0794 & 0.28 & 0.7770 & 2 \\
\hline
\end{tabular}

Table.4 Estimation of parameters of Mysore market

\begin{tabular}{|c|c|c|c|c|c|}
\hline \multicolumn{7}{|c|}{ Conditional Least Squares Estimation } \\
\hline Parameter & Estimate & Standard Error & t Value & Approx Pr $>|\mathbf{t}|$ & Lag \\
\hline MU & -2.0779 & 42.4816 & -0.05 & 0.9610 & 0 \\
\hline AR1,1 & -0.1311 & 0.0778 & -1.69 & 0.0937 & 1 \\
\hline AR1,2 & -0.1405 & 0.0780 & -1.80 & 0.0735 & 2 \\
\hline
\end{tabular}

Table.5 Box-Ljung statistic of ARIMA model for chilli price in selected markets

\begin{tabular}{|l|c|}
\hline Markets & Box-Ljung Statistic \\
\hline Bengaluru & 21.258 \\
\hline Byadgi & 22.630 \\
\hline Hubli & 24.672 \\
\hline Mysore & 21.794 \\
\hline
\end{tabular}


Table.6 Forecasted values of chilli price in selected markets

\begin{tabular}{|l|c|c|c|c|}
\hline \multicolumn{1}{|c|}{ Months } & Bengaluru & Byadgi & Hubli & Mysore \\
\hline June 2017 & 9081.17 & 7412.08 & 4317.02 & 7412.08 \\
\hline July 2017 & 8798.72 & 7854.15 & 4238.07 & 7854.15 \\
\hline August 2017 & 9778.34 & 8351.77 & 4251.74 & 8351.77 \\
\hline September 2017 & 10152.46 & 8338.53 & 4249.75 & 8338.53 \\
\hline October 2017 & 10294.65 & 7795.78 & 4250.41 & 7795.78 \\
\hline November 2017 & 10128.82 & 8571.17 & 4250.63 & 8571.17 \\
\hline
\end{tabular}

Forecasting the chilli prices in selected market

Using the ARIMA model, values were forecasted for six months. Considering the values from January, 2002 to May, 2017 next six months forecasted values are given in Table 6.

It is clear from the table that, in Bengaluru market forecasted prices were decreased in second month but increased gradually from third month and finally reported slightly decrease for the sixth month. In Byadgi market chilli prices increases gradually from first month of forecast till fourth month of the forecast and suddenly decrease in fifth month then rise in price was noticed. In Hubli market, for first and second month forecasted prices decreases but from third month onwards prices are stagnant with very minute fluctuation in price level. In Mysore forecasted values increase up to fourth month but fifth month of forecasted values decreases from fourth month and gain hike in succeeding month.

The mean absolute percentage error was worked out for all the markets which were 10.96 per cent, 10.66 per cent, 6.94 per cent and 5.40 per cent for Hubli, Mysore, Byadgi and Bengaluru markets, respectively. The Box-Ljung statistic of ARIMA model for chilli in selected markets indicated significant statistic for Hubli at 10 per cent. Therefore the model for Hubli market was returned and checked for Box-Ljung statistic and which could not be reduced further.

It can be concluded from the above results ARIMA model forecast has been done for the prices of chilli for six months. The prices of chilli are in ascending order in Bengaluru and Hubli and slightly fluctuating in Byadgi and Mysuru markets. Hence it can conclude that there are various extraneous factors which affect the price in selected markets. The forecasted prices help farmers to plan their production and marketing operations in such a way that, they can sell the produce during the months of high prices.

\section{References}

Batchelor, R., Amir, A. and Ilias, V., 2007, Forecasting of spot and forward prices in the international freight market. International J. Forecasting., 23(1): 101-114.

Bianchi, L., Jarrett, J. and Choudhary, H. R., 1998, Improving forecasting for telemarketing centers by ARIMA modeling with intervention. International J. Forecasting, 14(4): 497-504.

Conejo, J. A., Contreras, J., Espinola, R. and Miguel A. P., 2005, Forecasting electricity prices for a day-ahead poolbased electric energy market. International J. Forecasting., 21(3): 435-462.

Dhakre, D. S. and Bhattacharya, D., 2014, 
Price behaviour of potato in Agra market: A statistical analysis. Indian Res. J. Ext. Edu., 14 (2): 28-35.

Gupta, G.S., 1993, ARIMA model for forecasts on tea production in India. Indian Economic Journal, 41(2): 88110.

Manasa, P.B., 2010, Market dynamics and price forecasting of pigeon pea in south Karnataka. M.Sc. Thesis (Unpub.),
Univ. of Agric. Sci., Dharwad.

Mellor J.W., 1968, The functions of agricultural prices in economic development. Indian J. Agril. Econ., No. 1.

Yin, R. and Min, R. S., 1999, Forecasting short-term timber prices with Univariate ARIMA model. J. American Stat. Assoc., 25(1): 154-158.

\section{How to cite this article:}

Praveen Kumar, H. S., Prabhuling Tevari, Devendra Beeraladinni and Shivanand Kammar. 2020. Price Forecasting in Chilli Crop in Major Markets of Karnataka State, India. Int.J.Curr.Microbiol.App.Sci. 9(05): 3221-3226. doi: https://doi.org/10.20546/ijcmas.2020.905.382 